\title{
The effects of ultrasonication, fermentation with Lactobacillus sp., and dehydration on the chemical composition and microbial contamination of bovine colostrum
}

\author{
Elena Bartkiene, ${ }^{\star 1}$ Vadims Bartkevics, † Laura Elīna Ikkere, $\ddagger$ Iveta Pugajeva, $\ddagger$ Paulina Zavistanaviciute, ${ }^{*}$ \\ Vita Lele, ${ }^{*}$ Modestas Ruzauskas,§ Jurga Bernatoniene,\# Valdas Jakstas,II Dovile Klupsaite,ף Daiva Zadeike,ף \\ Pranas Viskelis, ${ }^{* *}$ and Grazina Juodeikieneף \\ *Department of Food Safety and Quality, Lithuanian University of Health Sciences, Tilzes St. 18, LT-47181 Kaunas, Lithuania \\ †Department of Chemistry, University of Latvia, Jelgavas iela 1, LV-1004 Riga, Latvia \\ łLaboratory of Food and Environmental Investigations, Institute of Food Safety, Animal Health and Environment "BIOR," Lejupes iela 3, \\ LV-1076 Riga, Latvia \\ §Institute of Microbiology and Virology, Lithuanian University of Health Sciences, Tilzes St. 18, LT-47181 Kaunas, Lithuania \\ \#Department of Drug Technology and Social Pharmacy, Institute of Pharmaceutical Technologies, Lithuanian University of Health Sciences, \\ Sukilèlių pr. 13, LT-5016 Kaunas, Lithuania \\ IIInstitute of Pharmaceutical Technologies, Lithuanian University of Health Sciences, Sukilèliu pr. 13, LT-5016 Kaunas, Lithuania \\ IDepartment of Food Sciences and Technology, Kaunas University of Technology, Radvilenu Rd. 19, LT-50254 Kaunas, Lithuania \\ ${ }^{* *}$ Biochemistry and Technology Laboratory, Institute of Horticulture, Lithuanian Research Centre for Agriculture and Forestry, Kauno St. 30, \\ LT-54333 Babtai, Lithuania
}

\begin{abstract}
The aim of this study was to evaluate the influence of ultrasonication, fermentation with Lactobacillus plantarum LUHS135 and Lactobacillus paracasei LUHS244, and different methods of dehydration on the chemical composition of bovine colostrum (BC), including the fatty acid and free amino acid profile and the content of micro- and macroelements. In addition, we analyzed the changes in lactic acid bacteria count, microbial contamination (aerobic mesophilic spore-forming bacteria, enterobacteria including Escherichia coli, and fungi/ yeasts), the abundance of biogenic amines, and the concentration of nucleotide monophosphates. Significant effects of different treatments on the free amino acid profile were established, and an increase of lysine concentration by 1.2 to $95.9 \%$ was observed in treated BC. All of the treatments reduced the concentration of cadaverine, histamine, and tyramine in $\mathrm{BC}$. The concentrations of macro- and microelements in $\mathrm{BC}$ followed the following order $\mathrm{Ca}>\mathrm{Na}>\mathrm{K}>\mathrm{Mg}$ and $\mathrm{Zn}>\mathrm{Fe}>$ $\mathrm{Sr}>\mathrm{Ba}>\mathrm{Mn}>\mathrm{Cu}>\mathrm{Al}>\mathrm{Se}>\mathrm{Mo}>\mathrm{Cr}>\mathrm{Ni}>\mathrm{Sn}$ $>\mathrm{Co}>\mathrm{Pb}>\mathrm{Cd}$. By combining the fermentation with Lactobacillus plantarum strain LUHS135 and vacuum drying, it was possible to increase the abundance of nucleotide monophosphates by more than $100 \%$. All of the treatments reduced the microbial contamination of BC. Thus, the combination of ultrasonication, fermen-
\end{abstract}

Received March 5, 2018.

Accepted March 26, 2018

${ }^{1}$ Corresponding author: elena.bartkiene@lsmuni.lt tation, and dehydration can be used for improving the properties and safety of BC.

Key words: bovine colostrum, ultrasonication and fermentation, dehydration, chemical composition, microbial contamination

\section{INTRODUCTION}

Bovine colostrum (BC) as functional food ingredient has been associated with the prevention and treatment of human diseases (Saad et al., 2016; Chae et al., 2017). Bovine colostrum has been demonstrated to possess antimicrobial activity, the ability to neutralize toxins (Støy et al., 2014), and to increase the growth of intestinal epithelial cells (Rathe et al., 2014). Based on these findings, $\mathrm{BC}$ is considered a very promising ingredient for functional food and nutraceutical formulations. However, the composition and physical properties of $\mathrm{BC}$ are highly variable due to several factors, including the preservation processes used (McGrath et al., 2016). Up to $60 \%$ of BC produced in the United States fail to meet the minimum requirements (i.e., $>50 \mathrm{~g} / \mathrm{L}$ of $\mathrm{IgG}$ and a total plate count of $<100,000 \mathrm{cfu} / \mathrm{mL}$, respectively; Morrill et al., 2012), raising concerns about the quality of BC. The specific composition of BC (high protein content and the presence of other sensitive or antimicrobial compounds) presents many challenges to industrial processing (McGrath et al., 2016), and only limited research has been carried out regarding the influence of various preservation methods on the detailed chemical composition of $\mathrm{BC}$. The most common methods for the preservation of $\mathrm{BC}$ are cooling or freezing 
(Ramya et al., 2016). The possible use of potassium sorbate to preserve BC has been reported (Denholm et al., 2017), and anaerobic fermentation can also be employed to reduce the contamination of BC (Saalfeld et al., 2016). Fermentation is a natural way to preserve $\mathrm{BC}$, but fermentation of proteinaceous material could lead to the formation of biogenic amines (BA); therefore, these compounds should be controlled. Another promising treatment for the preservation of $\mathrm{BC}$ is ultrasonication. Low-frequency ultrasonication can be used to improve the solubility of proteins and to increase the nutritional value of proteinaceous products (Bhandari and Zisu, 2016). Therefore, we hypothesized that the use of ultrasonication and fermentation, as well as different methods of dehydration, could be promising technologies for $\mathrm{BC}$ treatment to ensure biosafety parameters. However, changes of BC chemical composition should be controlled in addition to microbial contamination.

The aim of our study was to evaluate the influence of ultrasonication, fermentation with Lactobacillus plantarum strain LUHS135 and Lactobacillus paracasei strain LUHS244, and different methods of dehydration on the chemical composition of BC, including the fatty acid (FA) and free amino acid (FAA) profile and the content of micro- and macroelements. In addition, we analyzed the lactic acid bacteria (LAB) count, microbial contamination (aerobic mesophilic spore-forming bacteria, enterobacteria including Escherichia coli, and fungi/yeasts), as well as the concentrations of BA and nucleotide monophosphates (NM) in BC.

\section{MATERIALS AND METHODS}

\section{Materials}

Bovine colostrum was obtained within $2 \mathrm{~h}$ of calf delivery (from 20 cows) from Linas Agro agricultural company (Luksiai, Lithuania). The BC was selected in the winter at a farm of Lithuanian Black and White-Holstein dairy cows. The colostrum sample was collected at the same time and kept frozen $\left(-20^{\circ} \mathrm{C}\right)$ until analyzed in the laboratory. Animals were cared for according to the requirements for keeping, maintenance and use of animals intended for experimental and other scientific purposes (Lithuanian State Food and Veterinary Service, 2003). All cows passed general health examinations monthly throughout. Lactobacillus plantarum LUHS135 and Lactobacillus paracasei LUHS244 strains, which previously demonstrated good antimicrobial activity against a variety of pathogenic microorganisms, were selected for $\mathrm{BC}$ fermentation (Bartkiene et al., 2017). The LAB strains were stored at $-80^{\circ} \mathrm{C}$ in a Microbank system (Pro-Lab Diagnostics, Toronto, Canada) and grown in de Man, Rogosa, and Sharpe (MRS) broth (CM 0359, Oxoid, Basingstoke, $\mathrm{UK})$ at $30^{\circ} \mathrm{C}$ for $48 \mathrm{~h}$ before use.

\section{Ultrasonication, Fermentation, and Dehydration of $B C$}

Ultrasonication at low frequency $(37 \mathrm{kHz}, 160 \mathrm{~W})$ was used for the treatment of BC. The equipment employed was Proclean 3.0DSP model (Ulsonix, Zielona Góra, Poland). Each 20-g sample of BC was processed for $20 \mathrm{~min}$ at $40^{\circ} \mathrm{C}$ and each experiment was performed at least twice.

Lactobacillus plantarum strain LUHS135 and L. paracasei strain LUHS244 were grown in MRS medium (Biolife, Milan, Italy) at $30^{\circ} \mathrm{C}$. Two percent of the MRS solution ( $\mathrm{vol} / \mathrm{vol}$ ), in which were the strains multiplied, was inoculated into fresh medium and propagated for $18 \mathrm{~h}$; further multiplied strains (cell concentration 9.2 $\log 10 \mathrm{cfu} / \mathrm{mL}$, on average) were used for BC fermentation. Lactobacillus plantarum strain LUHS135 and $L$. paracasei strain LUHS244 were added to the BC (3\%, $\mathrm{vol} / \mathrm{vol}$ ), followed by fermentation in $\mathrm{CO}_{2}$ atmosphere in incubator (Memmert GmbH + Co. KG, Schwabach, Germany) for $24 \mathrm{~h}$ at $30^{\circ} \mathrm{C}$. The $\mathrm{BC}$ samples after fermentation with LUHS135 and LUHS244 strains, as well as nonfermented BC samples, were dried by (1) freeze drying for $72 \mathrm{~h}$ at $-40^{\circ} \mathrm{C}$ (Sublimator $3 \times 4 \times$ 5 , Zirbus Technology, Bad Grund, Germany, condenser temperature $-85^{\circ} \mathrm{C}$, pressure $2 \times 10^{-6} \mathrm{mPa}$ ), or (2) vacuum drying (temperature $45 \pm 2.0^{\circ} \mathrm{C}$ and pressure 6 $\times 10^{-3} \mathrm{mPa}$ in a XF020 vacuum dryer, France Etuves, Chelles, France).

In total, 11 samples were analyzed: fresh $\mathrm{BC}$, freezedried at $-40^{\circ} \mathrm{C}$, vacuum-dried at $45^{\circ} \mathrm{C}, \mathrm{BC}$ fermented with L. plantarum, BC fermented with L. paracasei, $\mathrm{BC}$ fermented with L. plantarum and freeze-dried at $-40^{\circ} \mathrm{C}$, BC fermented with L. paracasei and freezedried at $-40^{\circ} \mathrm{C}, \mathrm{BC}$ fermented with $L$. plantarum and vacuum-dried at $45^{\circ} \mathrm{C}, \mathrm{BC}$ fermented with $L$. paracasei and vacuum-dried at $45^{\circ} \mathrm{C}, \mathrm{BC}$ after ultrasonication and freeze drying at $-40^{\circ} \mathrm{C}$, and $\mathrm{BC}$ after ultrasonication and vacuum drying at $45^{\circ} \mathrm{C}$.

\section{Analysis of FA Composition in BC}

The FA composition of BC was determined using a $6890 \mathrm{~N}$ gas chromatograph (Agilent Technologies, Santa Clara, CA) equipped with a flame ionization detector (GC-FID), as described by Bartkiene et al. (2016). 


\section{Determination of the FAA Profile}

The FAA were extracted with $0.1 \mathrm{M} \mathrm{HCl}$ solution and the extracts were processed by ion exchange solid phase extraction and chloroformate derivatization using EZ:faast technology (Phenomenex, Torrance, CA), and then analyzed by GC-FID method (Agilent 6890N instrument) as described by Bartkiene et al. (2016). All elution and derivatization agents were provided by the EZ:faast amino acid analysis kit for protein hydrolysates by GC-FID or GC-nitrogen phosphorus detector.

\section{Analysis of the BA Content}

The procedures for extraction and determination of $\mathrm{BA}$ in BC samples were based on a report by BenGigirey et al. (1999). An Agilent 1200 HPLC instrument with diode array detector and Chemstation LC software (Aligent 1200 Series, Waldbronn, Germany) was used for this analysis.

\section{Analysis of Micro- and Macroelements in BC}

The analysis of micro- and macroelements in BC was performed by inductively coupled plasma mass spectrometry (ICP-MS) according to a published method (Bartkiene et al., 2016), using an Agilent 7700x ICP-MS instrument with Mass Hunter Work Station software for ICP-MS, version B.01.01 (Agilent Technologies, Tokyo, Japan).

\section{Analysis of NM in BC}

The analysis of NM in $\mathrm{BC}$ was performed using liquid samples (2 $\mathrm{g}$ each) and freeze-dried samples $(0.5 \mathrm{~g}$ each). The freeze-dried samples were dissolved in water before the analyses. The samples were mixed with 5 $\mathrm{mL}$ of aqueous $5 \%$ trichloroacetic acid solution. Each mixture was centrifuged (at $2,328 \times g$ for $15 \mathrm{~min}, 4^{\circ} \mathrm{C}$ ) and the supernatants were filtered through $0.2-\mu \mathrm{m}$ polyethersulfone membrane filters before the instrumental analyses.

The chromatographic analysis was performed using an Acquity UPLC system (Waters, Milford, MA) coupled to a QTrap 5500 mass selective detector (AB Sciex, Framingham, MA). The separation of NM was achieved with a Phenomenex Kinetex 1.7- $\mu \mathrm{m}$ C18 column $(100 \times 3.0 \mathrm{~mm})$. Water acidified with $0.1 \%$ formic acid (A) and acetonitrile (B) were used as the mobile phases (flow rate $=0.3 \mathrm{~mL} / \mathrm{min}$, ambient column temperature, injection volume $=10 \mu \mathrm{L}$, and gradient according to the following program: 0 min $100 \% \mathrm{~A}, 5$ $\min 99 \%$ A, $6.5 \min 95 \%$ A, $7 \min 0 \%$ A, $7.5 \min 0 \%$
A, 12 min $100 \%$ A). The conditions for the detection by MS-MS were curtain gas at 206,842.7 Pa, ion spray voltage $4,500 \mathrm{~V}$, temperature $550^{\circ} \mathrm{C}$, ion source gas at $275,790.3 \mathrm{~Pa}$, ion source gas at $413,685.4 \mathrm{~Pa}$, and declustering potential $30 \mathrm{~V}$. We used ion transitions adenosine monophosphate (AMP) $348 \rightarrow 136$, uridine monophosphate (UMP) $325 \rightarrow 97$, cytidine monophosphate (CMP) 324 $\rightarrow 112$, guanosine monophosphate (GMP) $364 \rightarrow 152$, and inosine monophosphate (IMP) $349 \rightarrow 137$. The collision energy for all analytes was 18 $\mathrm{eV}$, except that $25 \mathrm{eV}$ was used for AMP.

\section{Microbiological Analysis of BC}

Microbiological analyses (LAB, aerobic mesophilic spore-forming bacteria, the total number of enterobacteria, Escherichia coli, and fungi/yeast counts) were performed with $\mathrm{BC}$ samples that were ultrasonicated, fermented or not fermented, and before or after drying. For the evaluation of LAB count, a BC sample (10 g) was homogenized with $90 \mathrm{~mL}$ of $\mathrm{NaCl}$ solution (9 $\mathrm{g} / \mathrm{L}$ ). Serial dilutions of $10^{-4}$ to $10^{-8}$ with $\mathrm{NaCl}$ solution were used for sample preparation. Sterile MRS agar (CM0361, Oxoid) was used for bacterial growth on petri plates. The plates after seeding with the sample suspension were incubated under anaerobic conditions at $30^{\circ} \mathrm{C}$ for $72 \mathrm{~h}$. The number of aerobic mesophilic spore-forming bacteria was determined on plate count agar (CM0325, Oxoid). MacConkey and Tryptone Bile $\mathrm{X}$-glucuronide agar (both from Oxoid) were used for the determination of the total number of enterobacteria and Escherichia coli count (at $35-37^{\circ} \mathrm{C}$ for $18-24 \mathrm{~h}$ ). The fungi and yeasts were determined in chloramphenicol agar (CM0549, Oxoid) after incubation at $25^{\circ} \mathrm{C}$ for $5 \mathrm{~d}$. The number of microorganisms was calculated and expressed as $\log _{10}$ of colony-forming units per gram or milliliters. All of the results were expressed as the mean values of 5 determinations.

\section{Statistical Analysis}

For the chemical analysis (FA and FAA profile, BA content, micro- and macroelements, NM content), 2 parallel samples were analyzed 3 times. For the microbiological analysis, 5 repetitions were performed. All of the results were expressed as the mean values. The obtained data were subjected to ANOVA using the statistical package SPSS for Windows (Version 15.0, SPSS, Chicago, IL), and the effects of different treatments on the parameters of $\mathrm{BC}$ were evaluated. The calculated mean values were compared using Duncan's multiple range test with significance defined at $P \leq 0.05$. 


\section{RESULTS AND DISCUSSION}

\section{FA Composition of Treated BC Samples}

All of the investigated treatments of $\mathrm{BC}$ reduced the content of myristoleic (C14:1) acid (25.5\%, on average), $\alpha$-linolenic (C18:3n-3) acid (20.0\%, on average), butyric (C4:0) acid (17.9\%, on average), caproic (C6:0) acid (18.0\%, on average), caprylic (C8:0) acid (22.2\%, on average), capric (C10:0) acid (17.1\%, on average), lauric (C12:0) acid (18.0\%, on average), myristic (C14:0) acid $(14.0 \%$, on average), pentadecanoic (C15:0) acid (11.1\%, on average), and stearic (C18:0) acid (10.1\%, on average), as well as the total content of saturated fats $(5.1 \%$, on average), trans-fats $(43.3 \%$, on average), and n-3 fatty acids (31.7\%, on average; Table 1$)$. Opposite trends were found for the content of cis-10 heptadecenoic (C17:1) acid (increased by $33.3 \%$, on average, in the treated samples), oleic (C18:1n-9 cis) acid (increased by $12.2 \%$, on average, in the treated samples), linoleic (C18:2n-6 cis) acid (increased by $12.9 \%$, on average, in the treated samples), cis-8,11,14eicosatrienoic (C20:3n-6) acid (increased by $33.3 \%$, on average, in the treated samples), palmitic (C16:0) acid (increased by $3.5 \%$, on average, in the treated samples), arachidic (C20:0) acid (increased by $300.0 \%$, on average, in the treated samples), the total content of UFA (increased by $10.5 \%$, on average, in the treated samples), n- 6 FA (increased by $12.1 \%$, on average, in the treated samples), and n-9 FA (increased by $13.4 \%$, on average, in the treated samples) in treated $\mathrm{BC}$ samples. In most cases, significant effects of different treatments on the FA content $(P<0.001)$ were established. The influence of ultrasonication, fermentation with LAB strains LUHS135 and LUHS244, and different methods of dehydration also significantly affected the total content of SFA, the total content of UFA, as well the presence of $\mathrm{n}-3, \mathrm{n}-6, \mathrm{n}-9$, and trans-fatty acids in $\mathrm{BC}(P<$ 0.0001). Unsaturated FA elaidic (C18:1n-9 trans) acid, $\gamma$-linolenic (C18:3n-6) acid, cis-11-eicosenoeic (C20:1) acid, cis-11,14-eicosadienoic (C20:2) acid, cis-11,14,17eicosatrienoic (C20:3n-3) acid, cis-13,16-docosadienoic (C22:2) acid, and eicosapentaeneoic (C22:5n-3) acid, as well as SFA undecanoic (C11:0) acid, heneicosanoic $(\mathrm{C} 21: 0)$ acid, tricosanoic (C23:0) acid, and lignoceric $(\mathrm{C} 24: 0)$ acids were not detected in any of the treated or untreated BC samples.

Limited data were available about the FA composition of $\mathrm{BC}$, with most of the published studies reporting that $\mathrm{BC}$ contains high levels of $\mathrm{C} 18: 0$ and $\mathrm{C} 18: 1$ FA (Laakso et al., 1996; Palmquist, 2006). Bovine colostrum contains a lower amount of trans-FA, including cis-9,trans-11-octadecadienoic (C18:2) acid, compared with milk (Paszczyk et al., 2005). Essential FA are involved in many metabolic processes, with their deficiency or imbalance leading to illnesses (Willett, 2012). Many factors can be involved in changes of FA composition, including fermentation with LAB. It has been reported that some of the LAB strains can change the cis-9,cis-12 diene structure of C18 FA such as linoleic acid, $\alpha$-linolenic acid, and $\gamma$-linolenic acid into the conjugated cis-9,trans-11 and trans-9,trans-11 diene structures (Kishino et al., 2010). Finally, the treatment of $\mathrm{BC}$ significantly affected the concentrations of all FA (except C22:1n-9), and in treated BC samples higher total content of UFA, n- 6 FA, and n-9 FA was found; it should also be mentioned that trans fatty acids were not increased. According to our findings, the used treatments had no negative influence on FA.

\section{FAA Profile of $B C$}

The content of essential FAA and nonessential FAA in $\mathrm{BC}$ are presented in Table 2. The lowest amounts of Val, Leu, Ile, and Met were found in freeze-dried BC samples $(0.90 \pm 0.02,1.80 \pm 0.02,0.70 \pm 0.01$, and $0.50 \pm 0.02 \%$, respectively); however, freeze-dried BC samples contained the highest amounts of Lys (66.60 \pm $1.18 \%$ ). Ultrasonication increased the content of Val, Leu, Ile, Thr, and Met in BC samples, with the highest amounts of Val $(5.10 \pm 0.05$ and $4.30 \pm 0.03 \%)$ found in BC samples treated by ultrasonication and freeze drying or by ultrasonication and vacuum drying at $45^{\circ} \mathrm{C}$, respectively. The highest concentrations of Leu, Ile, and Met were established in BC samples after ultrasonication and vacuum drying at $45^{\circ} \mathrm{C}(12.90 \pm$ $0.04,5.00 \pm 0.04$, and $2.50 \pm 0.01 \%$, respectively), and the highest content of Thr was found in BC samples after ultrasonication and freeze drying $(2.80 \pm 0.01 \%)$. All of the used treatments increased the content of Lys in $\mathrm{BC}$ samples by 1.2 to $95.9 \%$ in ultrasonicated and vacuum-dried $\left(45^{\circ} \mathrm{C}\right) \mathrm{BC}$ and in freeze-dried $\mathrm{BC}$, respectively], except in the case when ultrasonication was combined with freeze drying.

Bovine colostrum has been proposed as a dietary supplement for humans due to its high protein content, as well as the presence of EAA that are important for balanced diet. Leucine is known to have a key role in muscle protein anabolism (Paddon-Jones et al., 2015), and histidine participates in the elimination of excess metal ions from the body and participates in the synthesis of collagen (Villacrés et al., 2015). Histidine is also recommended for muscle mass loss prevention after gastric bypass surgery (Katsanos et al., 2016). Threonine and isoleucine are involved in enzymatic activity regulation (Cárdenas, 2015), methionine has an essential role in protein synthesis (Xue et al., 2015), and tyrosine is converted in human body to melanin 


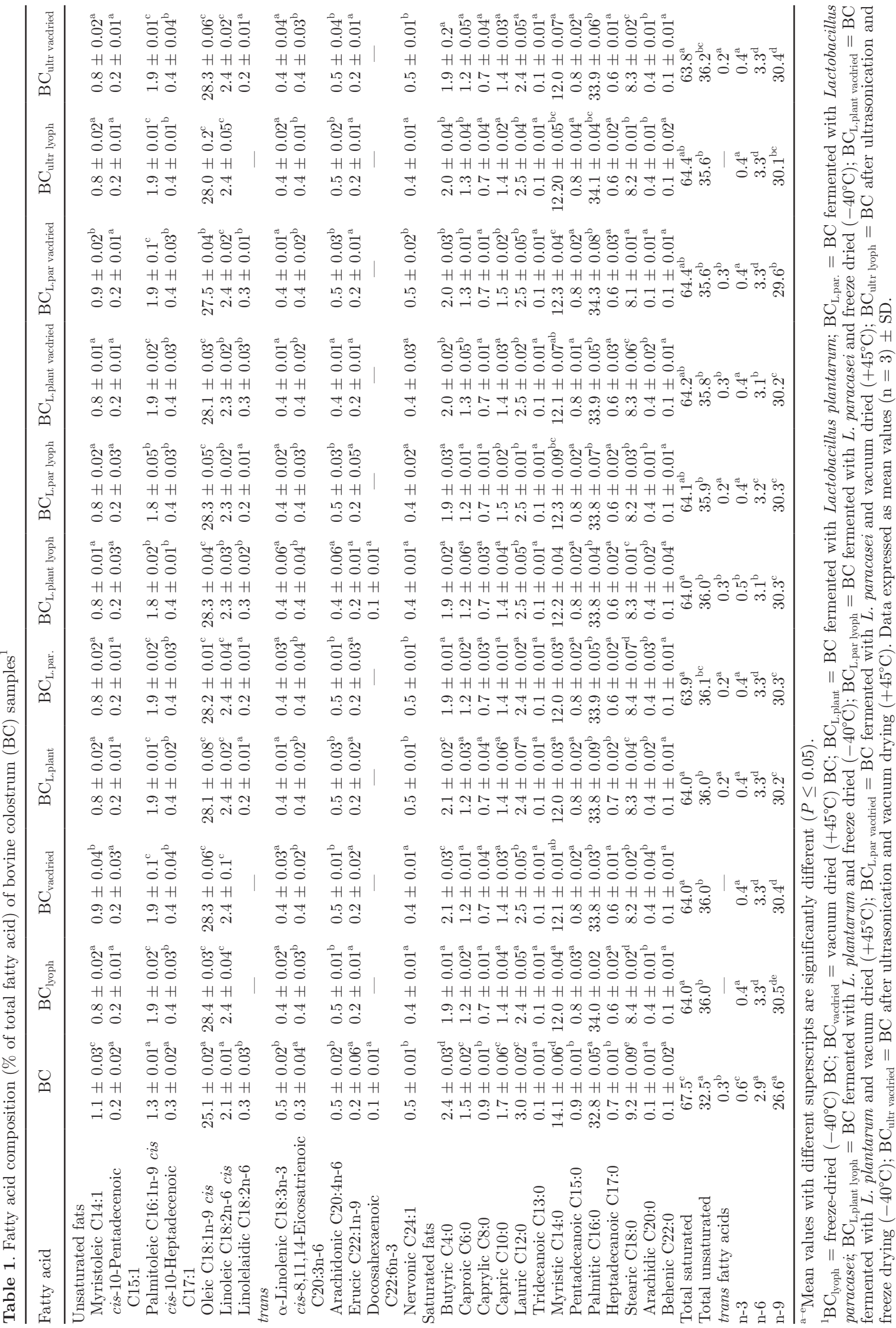




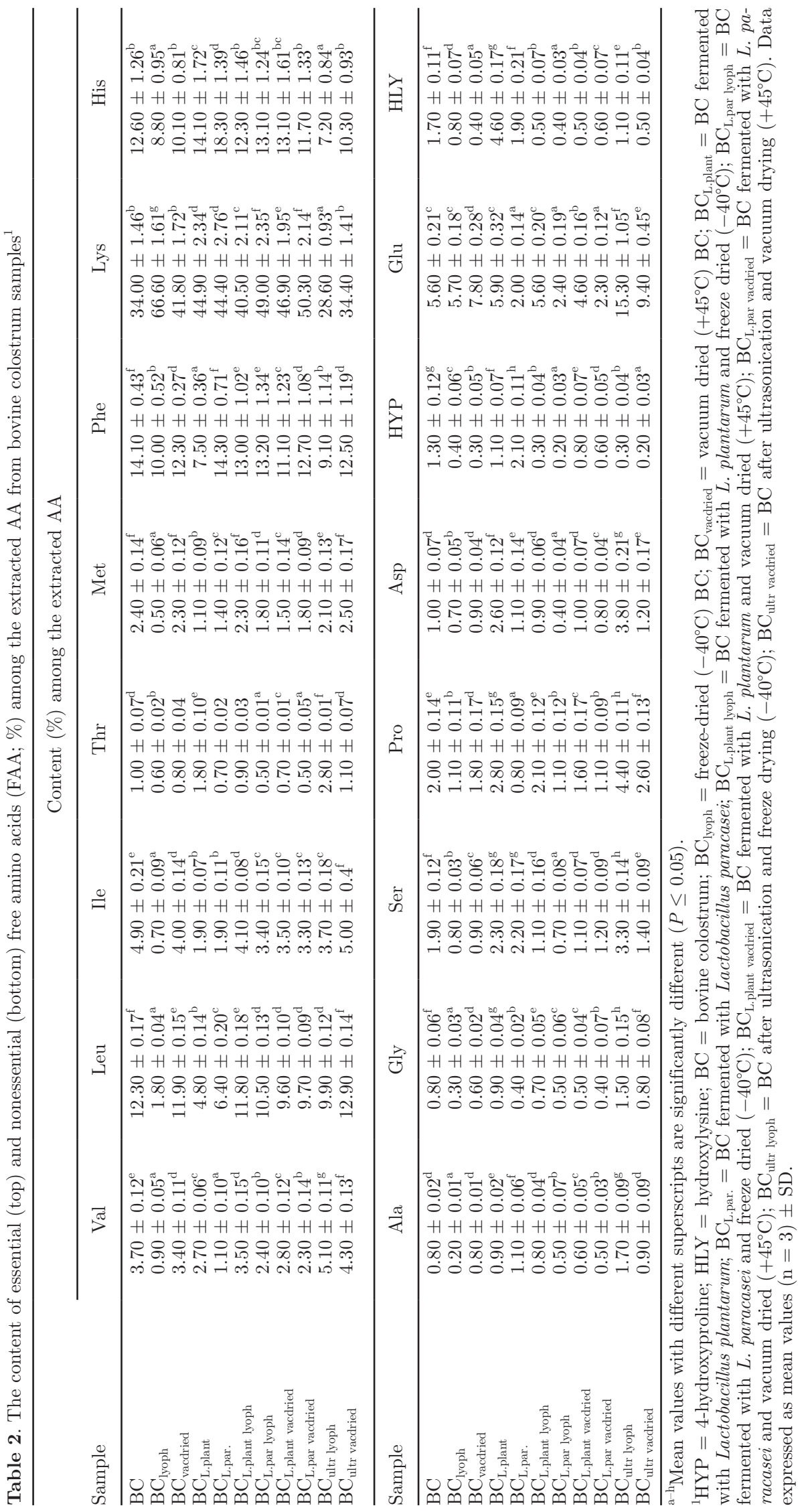


(Wu et al., 2016). The rest of the essential FAA are also involved in the biological tissue maintenance and repair. Thus, the obtained results showing an increase of FAA content in BC as a result of different treatments (with ultrasonication being the most effective) are very promising. Besides the enhancement of EAA content, the availability of NEAA is also important (Brestenský et al., 2015). The highest content of NEAA (Ala, Gly, Ser, Pro, Asp, and Glu) was found in BC samples after ultrasonication and freeze drying, compared with untreated samples (increased by 112.5, $87.5,73.7,120.0,280.0$, and $173.2 \%$, respectively). The results of ANOVA indicated a significant effect $(P<$ 0.0001 ) associated with the treatment method on the concentrations of EAA and NEAA in the BC samples. According to results obtained, an increase of FAA (essential and nonessential) content in $\mathrm{BC}$ as a result of different treatments (with ultrasonication being the most effective) can be very promising because it leads to modification of $\mathrm{BC}$ physiological properties as well as an increase in $\mathrm{BC}$ as a functional food component.

\section{Formation of BA During Treatment of BC}

The highest concentrations of $\beta$-phenylethylamine, putrescine, and spermine were found in $\mathrm{BC}$ samples after ultrasonication and freeze drying $(235.87 \pm 12.5$, $830.07 \pm 15.4$, and $7.85 \pm 0.11 \mathrm{mg} / \mathrm{kg}$, respectively; Table 3). The highest concentrations of cadaverine, histamine, and tyramine were found in untreated BC samples $(28.62 \pm 3.1,15.75 \pm 2.1$, and $662.68 \pm 12.4$ $\mathrm{mg} / \mathrm{kg}$, respectively). Statistical analysis showed a very weak positive correlation between Thr and tyramine ( $\mathrm{r}$ $=0.1593, P=0.002)$ and a weak negative correlation between the amino acid Lys and cadaverine $(\mathrm{r}=-0,3757$, $P=0.001)$ in BC samples. Furthermore, no correlations were found between His and histamine or between Phe and $\beta$-phenylethylamine. According to Montet and Ray (2016), arginine can be converted to agmatine and further to ornithine, which can be decarboxylated to putrescine. Likewise, lysine can be metabolized to cadaverine, and cadaverine by methylation to carnitine. Histidine can be decarboxylated to histamine, whereas tyramine, tryptamine, and $\beta$-phenylethylamine can by produced from tyrosine, tryptophan, and phenylalanine, respectively. Some BA are more toxic than others, but all BA are very important because they can potentiate the toxicity of each other, and the main precursors of $\mathrm{BA}$ are AA. Biogenic amines have specific physiological functions, but the consumption of products with high concentrations of BA can lead to health problems. For example, $\beta$-phenylethylamine, tryptamine, histamine, and tyramine can have negative effects on nervous and vascular systems (Papavergou et al., 2012); spermidine and spermine can lead to allergy (Sugita et al., 2007); and tyramine, spermidine, spermine, putrescine, and cadaverine are precursors of nitrosamines (Önal, 2007). According to our results, different processing regimens should be tested to ensure the safety of ultrasonicated $\mathrm{BC}$ with regard to the formation of $\beta$-phenylethylamine, putrescine, and spermine. Results of the ANOVA indicated that the treatment method had a significant effect $(P<0.0001)$ on the concentrations of $\mathrm{BA}$ in $\mathrm{BC}$ samples.

\section{Macro- and Microelement Content in BC}

Relatively little is known about the concentrations of micro- and macroelements in BC (McGrath et al., 2016). Our findings about the content of macro- and microelements in $\mathrm{BC}$ are presented in Table 4. The content of macroelements in $\mathrm{BC}$ samples ranged in the order of $\mathrm{Ca}>\mathrm{Na}>\mathrm{K}>\mathrm{Mg}$. Compared with untreated $\mathrm{BC}$ samples, a higher content of macroelements was found in all of the treated BC samples, with the highest content of macroelements observed in all the BC samples that were fermented with $L$. plantarum and freeze dried. Even though $\mathrm{Na}$ is an essential macro element, dietary intake of Na typically far exceeds the nutritional requirements, with about 70 to $75 \%$ of the total intake provided by processed foods. The presence of high concentrations of $\mathrm{Ca}$ in $\mathrm{BC}$ has been reported (McGrath et al., 2016). Casein micelles found in BC during the colostral period are less mineralized than later, during the lactation period. According to Jeong et al. (2009), the concentration of $\mathrm{K}$ in $\mathrm{BC}$ is $2,845 \mathrm{mg} /$ $\mathrm{kg}$, on average, and can range from 983 to $5,511 \mathrm{mg} /$ $\mathrm{kg}$. The reasons for such a high variation of $\mathrm{K}$ content in $\mathrm{BC}$ are unknown, but may be related to the nutritional status of the animal as well as environmental and genetic factors (Cashman, 2002).

The contents of microelements in $\mathrm{BC}$ samples ranged from $\mathrm{Zn}>\mathrm{Fe}>\mathrm{Sr}>\mathrm{Ba}>\mathrm{Mn}>\mathrm{Cu}>\mathrm{Al}>\mathrm{Se}>$ $\mathrm{Mo}>\mathrm{Cr}>\mathrm{Ni}>\mathrm{Sn}>\mathrm{Co}>\mathrm{Pb}>\mathrm{Cd}($ Table 5$)$. The presence of $\mathrm{Al}$ was observed in 3 out of $11 \mathrm{BC}$ samples, such as those that were fermented with L. plantarum and vacuum dried, ultrasonicated and freeze-dried, or ultrasonicated and vacuum dried, at the levels of 0.014 , 0.381 , and $1.302 \mathrm{mg} / \mathrm{kg}$ of dry weight, respectively. According to EFSA (2008), a tolerable weekly intake of $\mathrm{Al}$ is $1 \mathrm{mg} / \mathrm{kg}$ of $\mathrm{BW}$. The highest concentration of $\mathrm{Cr}$ was observed in vacuum-dried BC samples (0.249 $\mathrm{mg} / \mathrm{kg}$ of dry weight), whereas the lowest concentration was found in $\mathrm{BC}$ that was fermented with $L$. paracasei $(0.020 \mathrm{mg} / \mathrm{kg}$ of dry weight). Chromium in the form of $\mathrm{Cr}$ (III) plays a significant role in the metabolism of glucose, fats, and proteins in humans and animals, but data about tolerable daily intake of $\mathrm{Cr}$ is limited. The 


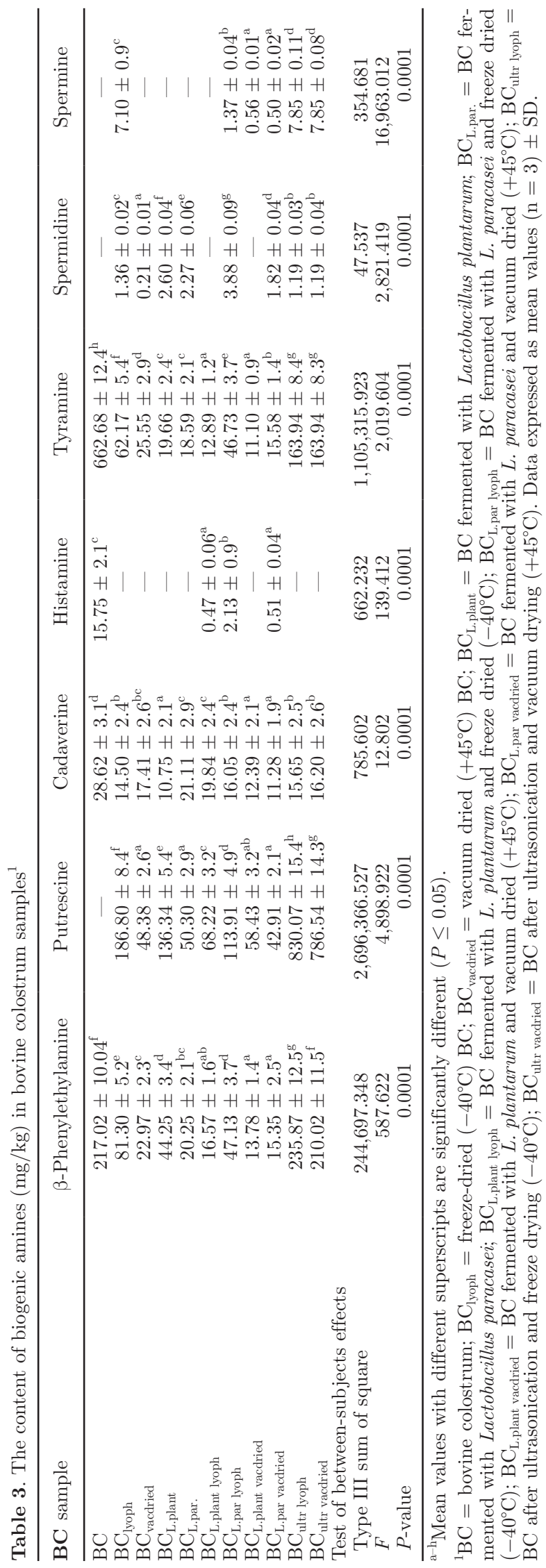

content of $\mathrm{Mn}$ in $\mathrm{BC}$ varied from 0.124 to $2.100 \mathrm{mg} /$ $\mathrm{kg}$ of dry weight in untreated $\mathrm{BC}$ and $\mathrm{BC}$ samples that were fermented with $L$. paracasei and vacuum dried, respectively. The highest concentration of Fe $(9.838 \mathrm{mg} /$ $\mathrm{kg}$ of dry weight) was found in vacuum-dried samples; however, the lowest concentrations of $\mathrm{Ni}, \mathrm{Cu}, \mathrm{Zn}$, and Sr $(0,0.127,28.6$, and $1.167 \mathrm{mg} / \mathrm{kg}$ of dry weight, respectively) were established in the same samples. The microelement $\mathrm{Ni}$ is involved in metabolism of Fe, and $\mathrm{Ni}$ deficiency in diet can lead to anemia (Shah et al., 2011). The microelements Co, I, Fe, and $\mathrm{Zn}$ are known to be often deficient in human nutrition (WHO, 1995). The concentrations of Co ranged from 0.003 to $0.037 \mathrm{mg} / \mathrm{kg}$ of dry weight in $\mathrm{BC}$ samples that were untreated or fermented with L. plantarum and vacuum dried, respectively. The highest content of Se was found in $\mathrm{BC}$ samples that were fermented with $L$. paracasei and freeze dried $(0.707 \mathrm{mg} / \mathrm{kg}$ of dry weight). Selenium is involved in the functions of antioxidant enzymes in humans and animals, and the deficiency of Se can lead to many disorders and illnesses (Kumar and Priyadarsini, 2014). Cadmium was found in 4 of the 11 analyzed BC samples $(0.001 \mathrm{mg} / \mathrm{kg}$ of dry weight in samples that were only freeze dried or samples that were fermented with $L$. paracase $i$ and then freeze dried; $0.004 \mathrm{mg} / \mathrm{kg}$ of dry weight in vacuum-dried BC samples; and $0.002 \mathrm{mg} /$ $\mathrm{kg}$ of dry weight in $\mathrm{BC}$ samples that were fermented with $L$. paracasei and vacuum dried). Cadmium is toxic and can lead to destabilization of the reproductive and nervous systems (ATSDR, 2008); tolerable monthly intake of $\mathrm{Cd}$ is $25 \mu \mathrm{g} / \mathrm{kg}$ of $\mathrm{BW}$ (FAO/WHO 2010). Arsenic and $\mathrm{Sb}$ were not detected $\mathrm{BC}$ samples, whereas $\mathrm{Pb}$ and $\mathrm{Sn}$ were detected in 1 and 2 samples, respectively, out of the 11 samples analyzed.

Most of the micro- and macroelements are essential for human nutrition, but can negatively affect health in excessive amounts (Zelalem and Chandravanshi, 2014). It has been reported that the average concentrations of $\mathrm{Cu}, \mathrm{Fe}, \mathrm{Zn}$, and $\mathrm{Mn}$ in $\mathrm{BC}$ were 1.7-, 10.7-, 10.9-, and 3.3-fold higher than the values for normal milk (Kehoe et al., 2007).

\section{Influence of Different Treatment Procedures on Concentration of NM in BC}

The concentrations of $\mathrm{NM}$ in $\mathrm{BC}$ samples are presented in Table 5. The results of the ANOVA indicated a significant effect $(P<0.0001)$ due to the treatment method on the concentrations of AMP, CMP, GMP, UMP, and IMP in BC samples. In the liquid samples group (untreated $\mathrm{BC}$ and $\mathrm{BC}$ fermented with the $\mathrm{LAB}$ strains LUHS135 and LUHS244), 4 of the 5 analyzed NM had lower concentrations; however, the concentration of CMP was higher in the $\mathrm{BC}$ samples fermented 


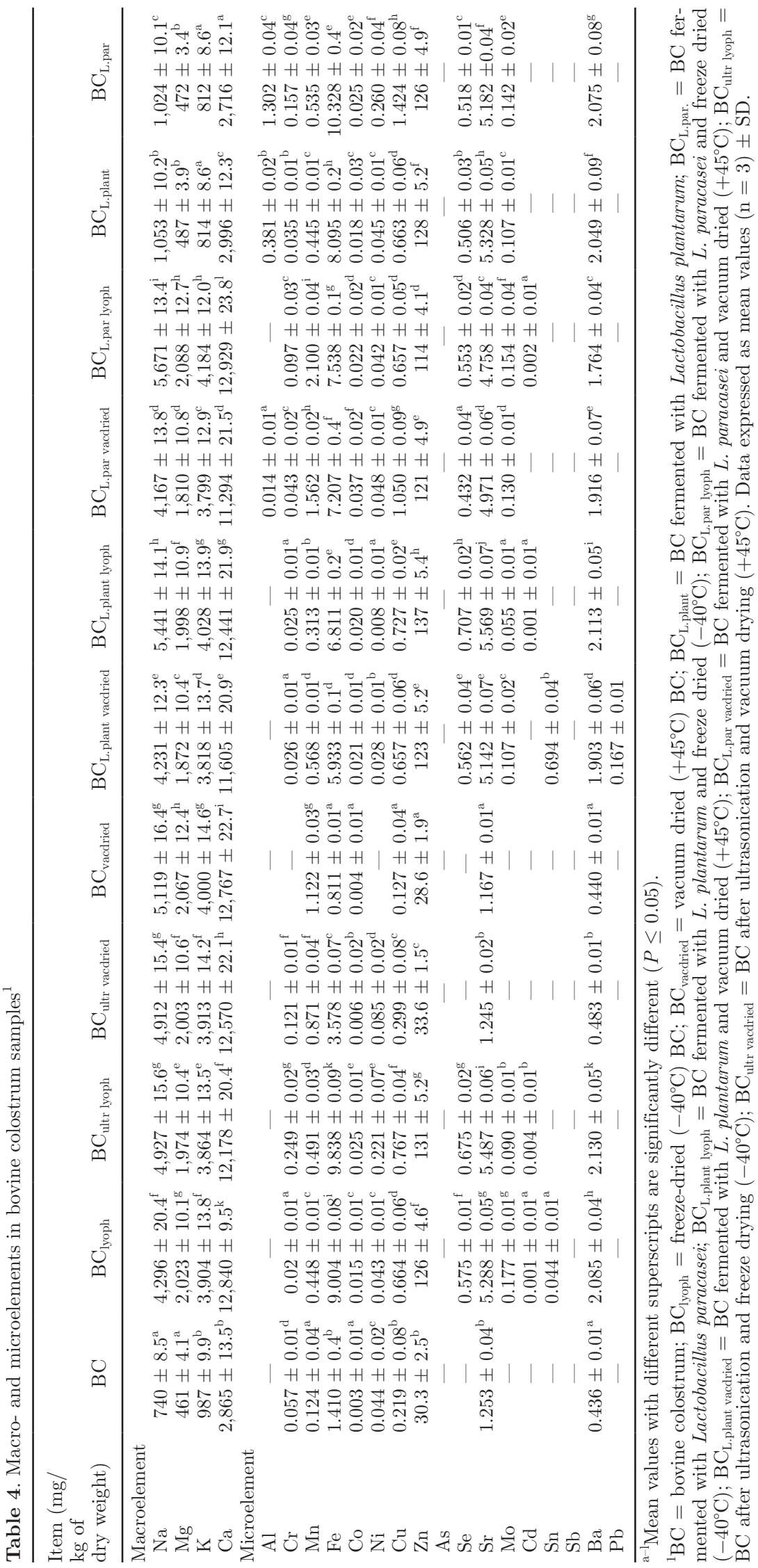


Table 5. The influence of different treatment methods on the concentrations of nucleotide monophosphates in $\mathrm{BC}^{1}$

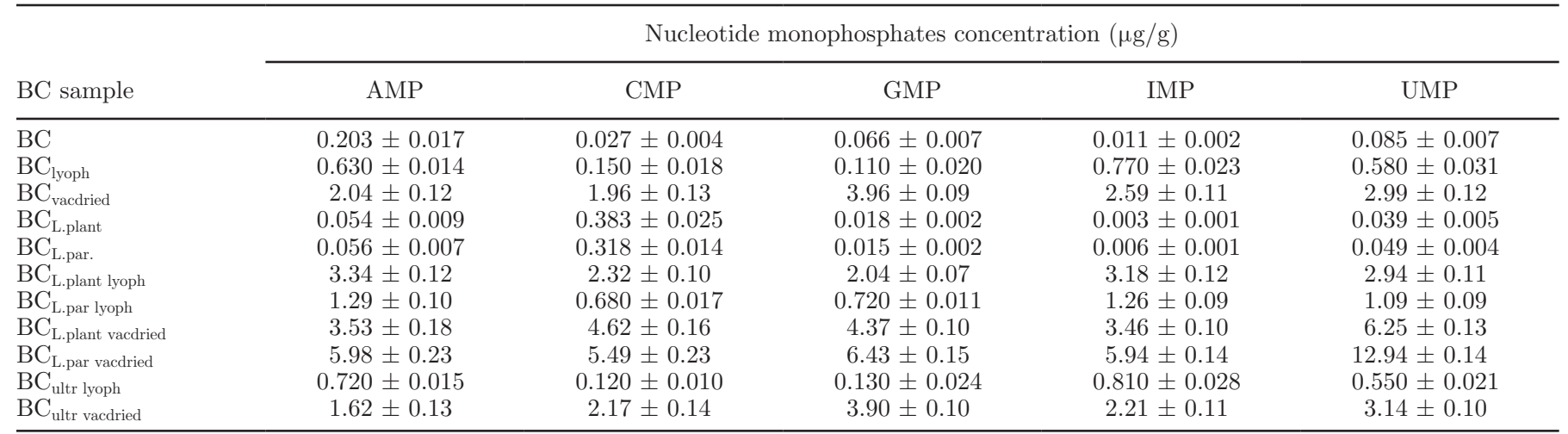

${ }^{1} \mathrm{CMP}=$ cytidine monophosphate; GMP $=$ guanosine monophosphate; IMP $=$ inosine monophosphate; UMP $=$ uridine monophosphate; $\mathrm{BC}$ $=$ bovine colostrum; $\mathrm{BC}_{\text {lyoph }}=$ freeze-dried $\left(-40^{\circ} \mathrm{C}\right) \mathrm{BC} ; \mathrm{BC}_{\text {vacdried }}=$ vacuum dried $\left(+45^{\circ} \mathrm{C}\right) \mathrm{BC} ; \mathrm{BC}_{\mathrm{L} . \text { plant }}=\mathrm{BC}$ fermented with Lactobacillus plantarum; $\mathrm{BC}_{\mathrm{L} . \text { par. }}=\mathrm{BC}$ fermented with Lactobacillus paracasei; $\mathrm{BC}_{\mathrm{L} \text {.plant lyoph }}=\mathrm{BC}$ fermented with L. plantarum and freeze dried $\left(-40^{\circ} \mathrm{C}\right) ;$ $\mathrm{BC}_{\mathrm{L} \text {.par lyoph }}=\mathrm{BC}$ fermented with $L$. paracasei and freeze dried $\left(-40^{\circ} \mathrm{C}\right) ; \mathrm{BC}_{\mathrm{L} \text {.plant vacdried }}=\mathrm{BC}$ fermented with $L$. plantarum and vacuum dried $\left(+45^{\circ} \mathrm{C}\right) ; \mathrm{BC}_{\mathrm{L} \text {.par vacdried }}=\mathrm{BC}$ fermented with $L$. paracasei and vacuum dried $\left(+45^{\circ} \mathrm{C}\right) ; \mathrm{BC}_{\text {ultr lyoph }}=\mathrm{BC}$ after ultrasonication and freeze drying $\left(-40^{\circ} \mathrm{C}\right) ; \mathrm{BC}_{\text {ultr vacdried }}=\mathrm{BC}$ after ultrasonication and vacuum drying $\left(+45^{\circ} \mathrm{C}\right)$. Data expressed as mean values $(\mathrm{n}=5) \pm \mathrm{SD}$.

with L. plantarum and L. paracasei (0.383 and 0.318 $\mu \mathrm{g} / \mathrm{kg}$, respectively). Among the BC samples in powder form, the highest content of the all analyzed NM was found in the BC samples after fermentation with L. paracasei and vacuum drying; compared with the average concentrations of NM, the BC samples after fermentation with $L$. paracasei and vacuum drying had AMP content that was higher by $149.8 \%$, CMP content higher by $150.8 \%$, GMP content higher by $137.5 \%$, IMP content higher by $135.0 \%$, and UMP content higher by $239.6 \%$. Taking into account that NM are involved in many essential physiological processes (synthesis of proteins, lipids, and carbohydrates), dietary supplements of nucleotides can be beneficial for humans under certain conditions (Dominguez-Álvarez et al., 2017). The EFSA NDA Panel (2014) recommends the supplementation of adapted milk products with up to $5 \mathrm{mg} / 100 \mathrm{kcal}$ of AMP, CMP, GMP, UMP, and IMP.

\section{Effects of Treatment Procedures on Bacteria, E. coli, and Fungi/Yeast Counts in BC}

Every year in the United States, approximately 48 million food-borne infections are reported (CDC, 2011). Interest is increasing for the development of food preservation techniques that can guarantee the safety and nutritional value of foods but at the same time are less time- and energy-consuming (Knorr et al., 2011). Pasteurization is the main proposed process for ensuring the safety of $\mathrm{BC}$ products; however, it can cause protein denaturation and lower the functional activity of BC (Lima et al., 2009). Our results showed that ultrasonication, fermentation, and dehydration could be used to reduce microbial contamination of $\mathrm{BC}$, because aerobic mesophilic spore-forming bacteria, enterobacte- ria, E. coli, and fungi/yeasts were not found in any of the treated $\mathrm{BC}$ samples (Table 6 ) and negative changes of the $\mathrm{BC}$ composition were not established. However, the LAB count ranged from 8.36 to $6.00 \log _{10} \mathrm{cfu} /$ $\mathrm{mL}$ in $\mathrm{BC}$ samples fermented with $L$. plantarum and in vacuum-dried BC samples, respectively. Antagonistic effects produced by LAB toward other organisms may play an important role in preserving of foods, and several authors have documented the ability of various LAB to inhibit growth of pathogenic microorganisms (Mokoena, 2017). Lactic acid bacteria are recognized as generally recognized as safe microorganisms and are commonly used as starter culture in many fermented foods of many countries. They produce various compounds, such as organic acids, diacetyl, hydrogen peroxide, bacteriocin, or bactericidal proteins, during lactic acid fermentations, and their ability to rapidly produce copious amounts of acidic end-products with a concomitant $\mathrm{pH}$ reduction is the major factor in these fermentations (Lindgren and Dobrogosz, 1990). Our results showed that fermentation could be used to reduce microbial contamination of BC. Ultrasound vibrations can cause liquids to expand and contract continuously; when liquids expand beyond their tensile strength, bubbles are formed, which eventually implode in a cavitation process and generate diverse physical and chemical processes at a microscopic level, such as extreme levels of temperature, shock waves, free radicals, reactive oxygen species formation, extreme levels of pressure, and high shear, which all ultimately provoke microbial inactivation (Bastarrachea et al., 2017). The effects of ultrasound on microorganisms are believed to consist of cell membrane disruption, damage of genetic information, denaturation of proteins, and cell lysis (Piyasena et al., 2003). Our results showed that ultrasonication, 
Table 6. The influence of different treatment methods on some microbiological parameters of bovine colostrum ${ }^{1}$

\begin{tabular}{|c|c|c|c|c|c|}
\hline BC sample & \multicolumn{5}{|c|}{$\log _{10} \mathrm{cfu} / \mathrm{g}$} \\
\hline $\begin{array}{l}\mathrm{BC} \\
\mathrm{BC}_{\text {lyoph }} \\
\mathrm{BC}_{\text {vacdried }} \\
\mathrm{BC}_{\mathrm{L} \cdot \text { plant }} \\
\mathrm{BC}_{\mathrm{L} \text {.par. }} \\
\mathrm{BC}_{\mathrm{L} \text {.plant lyoph }} \\
\mathrm{BC}_{\text {L.par lyoph }} \\
\mathrm{BC}_{\mathrm{L} \text {.plant vacdried }} \\
\mathrm{BC}_{\mathrm{L} \cdot \text { par vacdried }} \\
\mathrm{BC}_{\text {ultr lyoph }} \\
\mathrm{BC}_{\text {ultr vacdried }}\end{array}$ & $\begin{array}{c}6.39 \pm 0.12 \\
\mathrm{ND} \\
\mathrm{ND} \\
\mathrm{ND} \\
\mathrm{ND} \\
\mathrm{ND} \\
\mathrm{ND} \\
\mathrm{ND} \\
\mathrm{ND} \\
\mathrm{ND} \\
\mathrm{ND}\end{array}$ & $\begin{array}{c}6.04 \pm 0.09 \\
\text { ND } \\
\text { ND } \\
\text { ND } \\
\text { ND } \\
\text { ND } \\
\text { ND } \\
\text { ND } \\
\text { ND } \\
\text { ND } \\
\text { ND }\end{array}$ & $\begin{array}{l}8.32 \pm 0.10^{\mathrm{i}} \\
7.38 \pm 0.09^{\mathrm{e}} \\
6.00 \pm 0.09^{\mathrm{a}} \\
8.36 \pm 0.11^{\mathrm{i}} \\
8.15 \pm 0.08^{\mathrm{h}} \\
7.82 \pm 0.09^{\mathrm{g}} \\
7.11 \pm 0.06^{\mathrm{d}} \\
7.58 \pm 0.06^{\mathrm{f}} \\
6.86 \pm 0.11^{\mathrm{c}} \\
6.92 \pm 0.13^{\mathrm{c}} \\
6.30 \pm 0.09^{\mathrm{b}}\end{array}$ & $\begin{array}{l}8.26 \pm 0.07^{\mathrm{i}} \\
7.43 \pm 0.11^{\mathrm{h}} \\
6.02 \pm 0.04^{\mathrm{c}} \\
5.27 \pm 0.08^{\mathrm{b}} \\
5.00 \pm 0.05^{\mathrm{a}} \\
7.10 \pm 0.10^{\mathrm{g}} \\
6.65 \pm 0.09^{\mathrm{e}} \\
6.96 \pm 0.10^{\mathrm{f}} \\
6.98 \pm 0.10^{\mathrm{f}} \\
7.01 \pm 0.07^{\mathrm{g}} \\
6.45 \pm 0.04^{\mathrm{d}}\end{array}$ & $\begin{array}{c}6.24 \pm 0.06 \\
\text { ND } \\
\text { ND } \\
\text { ND } \\
\text { ND } \\
\text { ND } \\
\text { ND } \\
\text { ND } \\
\text { ND } \\
\text { ND } \\
\text { ND }\end{array}$ \\
\hline
\end{tabular}

${ }^{\mathrm{a}-\mathrm{i}}$ Mean values with different superscripts are significantly different $(P \leq 0.05)$.

${ }^{1} \mathrm{LAB}=$ lactic acid bacteria; $\mathrm{TBC}=$ number of aerobic mesophilic sporeforming bacteria; $\mathrm{ND}=$ not detected; $\mathrm{BC}=$ bovine colostrum; $\mathrm{BC}_{\text {lvoph }}$ $=$ freeze-dried $\left(-40^{\circ} \mathrm{C}\right) \mathrm{BC} ; \mathrm{BC}_{\text {vacdried }}=$ vacuum dried $\left(+45^{\circ} \mathrm{C}\right) \mathrm{BC} ; \mathrm{BC}_{\mathrm{L} . \text { plant }}=\mathrm{BC}$ fermented with Lactobacillus plantarum; $\mathrm{BC}_{\mathrm{L} . \text { par. }}=\mathrm{BC}$ fermented with Lactobacillus paracasei; $\mathrm{BC}_{\mathrm{L} . \text { plant lyoph }}=\mathrm{BC}$ fermented with L. plantarum and freeze dried $\left(-40^{\circ} \mathrm{C}\right) ; \mathrm{BC}_{\mathrm{L} . \mathrm{par} \text { lyoph }}=\mathrm{BC}_{\text {fermented }}$ with $L$. paracasei and freeze dried $\left(-40^{\circ} \mathrm{C}\right) ; \mathrm{BC}_{\mathrm{L} \text {.plant vacdried }}=\mathrm{BC}$ fermented with $L$. plantarum and vacuum dried $\left(+45^{\circ} \mathrm{C}\right) ; \mathrm{BC}_{\mathrm{L} . \mathrm{par}}$ vacdried $=\mathrm{BC}$ fermented with $L$. paracasei and vacuum dried $\left(+45^{\circ} \mathrm{C}\right) ; \mathrm{BC}_{\text {ultr lyoph }}=\mathrm{BC}$ after ultrasonication and freeze drying $\left(-40^{\circ} \mathrm{C}\right) ; \mathrm{BC}_{\mathrm{ultr}}$ vacdried $=\mathrm{BC}$ after ultrasonication and vacuum drying $\left(+45^{\circ} \mathrm{C}\right)$. Data expressed as mean values $(\mathrm{n}=5) \pm \mathrm{SD}$.

fermentation, and dehydration could be used to reduce microbial contamination of BC; however, more investigations are needed to evaluate the influence of these treatment methods on sensitive biologically active compounds in BC.

\section{CONCLUSIONS}

Ultrasonication and fermentation, as well as different methods of dehydratation, can be promising technologies for $\mathrm{BC}$ treatment. The treatments significantly affected the concentrations of most FA, and we found higher total content of UFA, n- 6 FA, and n-9 FA in treated BC samples; however, content of trans FA were not increased. An increase of FAA content in BC as a result of different treatments (with ultrasonication being the most effective) can be very promising because it leads to an increase in BC functionality. All of the treatments reduced the presence of cadaverine, histamine, and tyramine in BC. The concentrations of macro- and microelements in $\mathrm{BC}$ were in the order of $\mathrm{Ca}>\mathrm{Na}>\mathrm{K}$ $>\mathrm{Mg}$ and $\mathrm{Zn}>\mathrm{Fe}>\mathrm{Sr}>\mathrm{Ba}>\mathrm{Mn}>\mathrm{Cu}>\mathrm{Al}>\mathrm{Se}$ $>\mathrm{Mo}>\mathrm{Cr}>\mathrm{Ni}>\mathrm{Sn}>\mathrm{Co}>\mathrm{Pb}>\mathrm{Cd}$, respectively. The concentrations of nucleotide monophosphates in $\mathrm{BC}$ were significantly increased by using a combination of fermentation with LUHS135 and vacuum drying. All of the treatments reduced the microbial contamination of $\mathrm{BC}$, as LAB count ranged from 8.36 to $6.00 \log _{10}$ $\mathrm{cfu} / \mathrm{mL}$. Finally, we concluded that a combination of ultrasonication, fermentation, and dehydration could be used to reduce microbial contamination of $\mathrm{BC}$; however, more investigations are needed to evaluate the influence of these treatment methods on sensitive biologically active compounds in $\mathrm{BC}$.

\section{ACKNOWLEDGMENTS}

This research was funded by the European Regional Development Fund according to the supported activity 'Research Projects Implemented by World-class Researcher Groups' under Measure No. 01.2.2-LMTK-718.

\section{REFERENCES}

ATSDR. 2008. Toxicological profile for cadmium. Draft. Agency for Toxic Substances and Disease Registry (ATSDR), United States Department of Health and Human Services, Atlanta, GA.

Bartkiene, E., V. Bartkevics, V. Starkute, V. Krungleviciute, D. Cizeikiene, D. Zadeike, G. Juokeikiene, and Z. Maknickiene. 2016. Chemical composition and nutritional value of seeds of Lupinus luteus L., L. angustifolius L. and new hybrid lines of L. angustifolius L. Zemdirbyste-Agriculture 103:107-114.

Bartkiene, E., M. Ruzauskas, V. Lele, P. Zavistanaviciute, J. Bernatoniene, V. Jakstas, L. Ivanauskas, D. Zadeike, D. Klupsaite, P. Viskelis, J. Bendoraitiene, V. Navikaite-Snipaitiene, and G. Juodeikiene. 2017. Development of antimicrobial gummy candies with addition of bovine colostrum, essential oils and probiotics. Int. J. Food Sci. Technol. 53:1277-1235. https://doi.org/10.1111/ijfs .13701 .

Bastarrachea, L. J., M. Walsh, S. P. Wrennb, and R. V. Tikekar. 2017. Enhanced antimicrobial effect of ultrasound by the food colorant Erythrosin B. Food Res. Int. 100:344-351.

Ben-Gigirey, B., J. M. V. B. De Sousa, T. G. Villa, and J. BarrosVelazquez. 1999. Histamine and cadaverine production by bacteria isolated from fresh and frozen albacore (Thunnus alalunga). J. Food Prot. 62:933-939.

Bhandari, B., and B. Zisu. 2016. Effect of ultrasound treatment on the evolution of solubility of milk protein concentrate powder. Pages 1383-1401 in Handbook of Ultrasonics and Sonochemistry. Springer, Singapore.

Brestenský, M., S. Nitrayová, P. Patráš, J. Heger, and J. Nitray. 2015. Branched chain amino acids and their importance in nutrition. J. Microbiol. Biotechnol. Food Sci. 5:197-202.

Cárdenas, M. L. 2015. Understanding mechanisms of enzyme co-operativity: The importance of not being at equilibrium. Perspect. Sci. $4: 10-16$. 
Cashman, K. Y. 2002. Macroelements, nutritional significance. In Encyclopedia of Dairy Sciences. H. Roginski, J. W. Fuquay, and P. F. Fox, ed. Elsevier Academic Press, London, UK.

Centers for Disease Control and Prevention (CDC). 2011. Vital signs: Incidence and trends of infection with pathogens transmitted commonly through food - Foodborne diseases active surveillance network, 10 U. S. sites, 1996-2010. MMWR Morb. Mortal. Wkly. Rep. 60:749-755.

Chae, A., A. Aitchison, A. S. Day, and J. I. Keenan. 2017. Bovine colostrum demonstrates anti-inflammatory and antibacterial activity in in vitro models of intestinal inflammation and infection. J. Funct. Foods 28:293-298.

Denholm, K. S., J. C. Hunnam, E. L. Cuttance, and S. McDougall 2017. Influence of preservation methods on the quality of colostrum sourced from New Zealand dairy farms. N. Z. Vet. J. 65:264-269.

Dominguez-Álvarez, J., M. Mateos-Vivasa, E. Rodriguez-Gonzalo, D. García-Gómez, M. Bustamante-Rangel, M.-M. Delgado Zamarreno, and R. Carabias-Martíneza. 2017. Determination of nucleosides and nucleotides in food samples by using liquid chromatography and capillary electrophoresis. TrAC. Trends Analyt. Chem. $92: 12-31$.

EFSA. 2008. Safety of aluminium from dietary intake. Scientific opinion of the panel on food additives, flavourings, processing aids and food contact materials (AFC). EFSA J. 754:3-34.

EFSA NDA Panel (EFSA Panel on Dietetic Products, Nutrition and Allergies). 2014. Scientific opinion on the essential composition of infant and follow-on formulae. EFSA J. 12:3760. https://doi.org/ $10.2903 /$ j.efsa.2014.3760

FAO/WHO. 2010. Evaluation of certain food additives. Seventy-first report of the Joint FAO/WHO Expert Committee on Food Additives. World Health Organization. Food and Agriculture Organization of the United Nations, Rome, Italy.

Jeong, S. G., J. S. Ham, D. H. Kim, C. N. Ahn, and H. S. Chae 2009. Physiochemical properties of colostrum by milking time of Gyeonggi Province. Han-gug Chugsan Sigpum Hag-hoeji 29:445456.

Katsanos, C. S., J. A. Madura, and L. R. Roust. 2016. Essential amino acid ingestion as an efficient nutritional strategy for the preservation of muscle mass following gastric bypass surgery. Nutrition 32:9-13.

Kehoe, S. I., B. M. Jayarao, and A. J. Heinrichs. 2007. A survey of bovine colostrum composition and colostrum management practices on Pennsylvania farms. J. Dairy Sci. 90:4108-4116.

Kishino, S., J. Ogawa, A. Ando, K. Yokozeki, and S. Shimizu. 2010. Microbial production of conjugated $\gamma$-linolenic acid by Lactobacillus plantarum AKU 1009a. J. Appl. Microbiol. 108:2012-2018.

Knorr, D., A. Froehling, H. Jaeger, K. Reineke, O. Schlueter, and K. Schoessler. 2011. Emerging technologies in food processing. Annu. Rev. Food Sci. Technol. 2:203-235.

Kumar, B. S., and K. I. Priyadarsini. 2014. Selenium nutrition: How important is it? Biomed. Prev. Nutr. 4:333-341.

Laakso, P., P. Manninen, J. Makinen, and H. Kallio. 1996. Postparturition changes in the triacylglycerols of cow colostrum. Lipids 31:937-943.

Lima, A. L., P. Pauletti, I. Susin, and R. Machado-Neto. 2009. Fluctuation of serum variables in goats and comparative study of antibody absorption in new-born kids using cattle and goat colostrum. Rev. Bras. Zootec. 38:2211-2217.

Lindgren, S. E., and W. J. Dobrogosz. 1990. Antagonistic activities of lactic acid bacteria in food and feed fermentations. FEMS Microbiol. Rev. 7:149-163.

Lithuanian State Food and Veterinary Service. 2003. Requirements for keeping, maintenance and use of animals intended for experimental and other scientific purposes. Valstybès Žinios 2003-01-25, No. 9-334.

McGrath, B. A., P. Fox, P. L. H. McSweeney, and A. L. Kelly. 2016. Composition and properties of bovine colostrum: A review. Dairy Sci. Technol. 96:133-158.

Mokoena, M. P. 2017. Lactic acid bacteria and their bacteriocins: Classification, biosynthesis and applications against uropatho- gens: A mini-review. Molecules 22:1255. https://doi.org/10.3390/ molecules22081255.

Montet, D., and R. C. Ray. 2016. Fermented Foods. Part 1: Biochemistry and Biotechnology. CRC Press, Boca Raton, FL.

Morrill, K. M., E. Conrad, A. Lago, J. Campbell, and J. Quigley. 2012. Nationwide evaluation of quality and composition of colostrum on dairy farms in the United States. J. Dairy Sci. 95:3997-4005.

Önal, A. 2007. A review: current analytical methods for the determination of biogenic amines in foods. Food Chem. 103:1475-1486.

Paddon-Jones, D., W. W. Campbell, P. F. Jacques, S. B. Kritchevsky, and L. L. Moore. 2015. Protein and healthy aging. Am. J. Clin. Nutr. 101:1339-1345.

Palmquist, D. L. 2006 Milk fat: origin of fatty acids and influence of nutritional factors thereon. Pages 43-92 in Advanced Dairy Chemistry. Vol. 2. P. F. Fox and P. L. H. McSweeney, ed. Springer, Boston, MA.

Papavergou, E. J., I. N. Savvaidis, and I. A. Ambrosiadis. 2012. Levels of biogenic amines in retail market fermented meat products. Food Chem. 135:2750-2755.

Paszczyk, B. Z. Zegarska, and Z. Borejszo. 2005. The contents of trans fatty acids and CLA in cow colostrum and milk fat in the early lactation period. Czech J. Food Sci. 23:159-165.

Piyasena, P., E. Mohareb, and R. C. McKellar. 2003. Inactivation of microbes using ultrasound: A review. Int. J. Food Microbiol $87: 207-216$.

Ramya, S. B., D. Ramasamy, and V. Dhineshkumar. 2016. Effects of refrigeration, deep freezing-spray drying and pasteurization on igg bovine colostrum preservation. Int. J. Dairy Sci. 3:35-37.

Rathe, M., K. Müller, P. T. Sangild, and S. Husby. 2014. Clinical applications of bovinecolostrum therapy: A systematic review. Nutr. Rev. 72:237-254.

Saad, K., M. G. M. Abo-Elela, and K. A. A. El-Baseer. 2016. Effects of bovine colostrum on recurrent respiratory tract infections and diarrhea in children. Medicine 95:e4560.

Saalfeld, M. H., D. I. B. Pereira, J. S. S. Valente, J. L. Borchardt, and C. F. Weissheimer. 2016. Effect of anaerobic bovine colostrum fermentation on bacteria growth inhibition. Ciênc. Rural 46:2152-2157.

Shah, F., T. G. Kazi, H. I. Afridi, N. Kazi, and J. A. Baig. 2011. Evaluation of status of trace and toxic metals in biological samples (scalp hair, blood, and urine) of normal and anemic children of two age groups. Biol. Trace Elem. Res. 141:131-149.

Støy, A. C., P. M. Heegaard, T. Thymann, M. Bjerre, K. Skovgaard, and M. Boye. 2014. Bovine colostrum improvesintestinal function following formula-induced gut inflammation in pretermpigs. Clin. Nutr. 33:322-329.

Sugita, Y., K. Takao, Y. Toyama, and A. Shirahata. 2007. Enhancement of intestinal absorption of macromolecules by spermine in rats. Amino Acids 33:253-260.

Villacrés, E., V. Allauca, E. Peralta, G. Insuasti, and J. Alvarez. 2015. Germination, an effective process to increase the nutritional value and reduce non-nutritive factors of lupine grain (Lupinus mutabilis Sweet). Int. J. Food Sci. Nutr. Eng. 5:163-168.

WHO. 1995. Evaluation of certain food additives and contaminants. World Health Organ. Tech. Rep. Ser. 859:1-54.

Willett, W. C. 2012. Dietary fats and coronary heart disease. J. Intern. Med. 272:13-24.

Wu, Q., A. Fang, H. Li, Y. Zhang, and S. Yao. 2016. Enzymaticinduced upconversion photoinduced electron transfer for sensing tyrosine in human serum. Biosens. Bioelectron. 77:957-962.

Xue, M., J. Long, Q. Jiang, M. Wang, S. Chen, Q. Pang, and Y. He. 2015. Distinct patterns of the histone marks associated with recruitment of the methionine chain-elongation pathway from leucine biosynthesis. J. Exp. Bot. 66:805-812.

Zelalem, K. A., and B. S. Chandravanshi. 2014. Levels of essential and non-essential elements in raw and processed Lupinus albus L. (white lupin, gibto) cultivated in Ethiopia. Afr. J. Food Agric. Nutr. Dev. 14:2015-2035. 